\title{
Research on and Implementation of the Logistics Warehouse Management System
}

\author{
Jie Chang ${ }^{1}$ \\ ${ }^{1}$ Shandong Yingcai University,Jinan,Shandong, 250104 China
}

\begin{abstract}
In this paper, we conduct research on the modern logistics warehouse management system. Enterprise supplies all activities were around to ensure that production and other tasks planned to finish the fundamental goal, therefore, on the one hand to accounting supplies must dosage, on the other hand to organize the material resource, including the enterprise internal resources and purchased from external resources. To make the enterprise production and the other activities can properly and efficiently, objective demand supplies need to coordinate between cohesion and material resources, to supplies comprehensive balance work. Under this circumstance, we implement the system with the theoretical analysis to enhance the performance of the traditional ones.
\end{abstract}

Keywords- Logistics Warehouse, Management System, Implementation, Systematic Design.

\section{Introduction}

Warehouse by warehouse to storage and keeping of goods, as the production of material storage, and the development of productive forces, the development trend of storage is one of the important links of the circulation of commodities which is the backbone of logistics activities. To maintain the social reproduction process smoothly, it is necessary to store a certain amount of material, in order to meet the needs of the social production and the consumption within a certain time. It is reflects the factory supplies comprehensive place of activity as is a hub connecting production, supply and marketing, to promote the production efficiency play an important supporting role. At the same time, around the warehousing physical activities, clear and general accurate accounts statements, documents, business accounting of accounting department of accurate information at same time, therefore the warehousing logistics, information flow and the document flow [1-3]. 


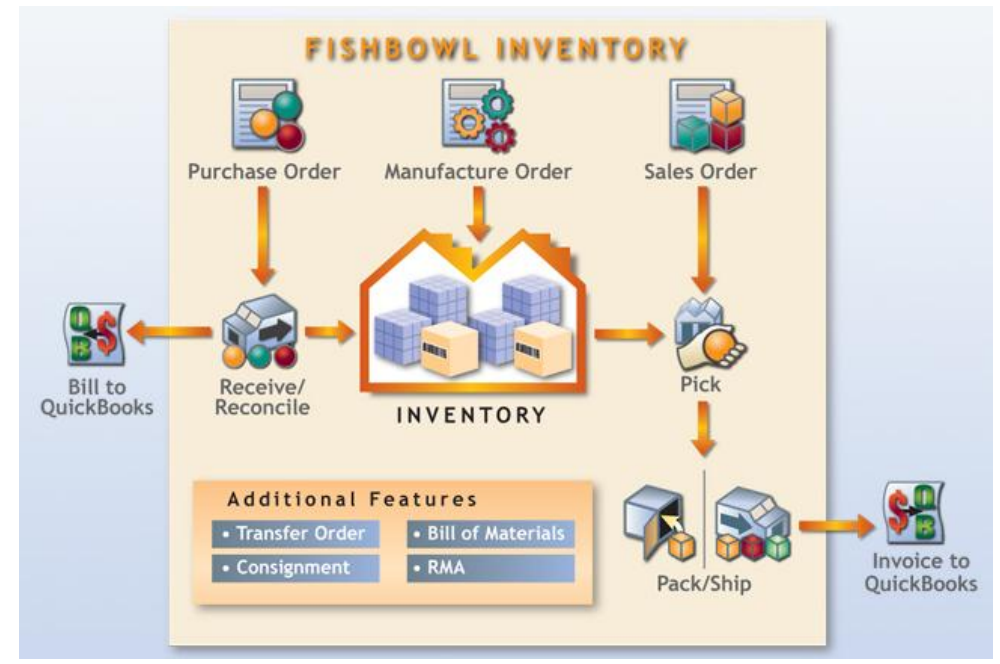

Figure 1. The Demonstrative Illustration of the Modern Logistics Warehouse System

As shown in the figure one, we illustrate the modern logistics warehouse system. The intelligent logistics is intelligent transportation system on the basis of electronic business operation system of the logistics service. It through the intelligent transportation system to solve the logistics operation of the real-time information collection, and the collection of information analysis and processing, through in each link of logistics in the information transmission, for the logistics managers and users to provide detailed information and consulting services. Under operating environment of electronic commerce, to provide customers with the value-added logistics services. The development trend of the intelligent logistics mainly reflects in the following respects. (1) Intelligent logistics, the logistics service can be extended upward to the market research and forecasting, purchasing and order processing: extends downward to distribution, logistics consulting, logistics scheme selection and the planning, inventory control, policy recommendations, payment collection and settlement, education and training, logistics system design and planning of production and so on. (2) When providing logistics service, logistics process tracking technology of the intelligent logistics, e-commerce in the auto order, based on web technology support will greatly increase the logistics service convenience and shortcut. (3)
Intelligent integrated logistics planning and design of the simulation technology in logistics, distributed storage management, inventory control technology and network scheduling and optimization technology to logistics transportation system will provide technical guarantee for the rapid response [4-5].

In this paper, we conduct research on the logistics warehouse management system. Material is the material for production and operation enterprises, an enterprise want to improve the efficiency, cost savings, this work must be prepared to the material management. Material management system in the capitalist industrial production had already begun to take the model, after more than a century of the development, has formed the set of scientific integrity system, and has accumulated rich management experience, for enterprises to establish a set of strict material management system laid the foundation. Contemporary with progress of science and technology, the invention of new technology ceaselessly, while the material management automation technology have been widely used which brought great convenience to the material management work.

\section{Our Proposed Methodology}


The Principles of Logistics Warehousing. In today's era of basic material abundance, the logistics industry has become a guarantee for a country one of the important basic conditions for its economic development. The composition of the modern logistics mainly includes the transportation of goods, warehousing, packaging, transportation and handling, circulation processing, and the related logistics information, and a series of links, as long as any of them a link to create the problems, will affect the whole logistics process is complete. In the whole logistics process, logistics warehouse in it and in a buffer, regulate and a balance status. Therefore, the construction of logistics warehouse construction has become the important position in the whole logistics industry chain.

Based on the literature review, the principles of finalizing the warehousing system could be general summarized as the follows. (1) Warehouse location matter circulation of logistics costs and the degree of impact on the environment. In storage location, should be from the perspective of comprehensive, integrated, strategic system, the green, environmental protection, economy, factors such as cost into the storage location decisions, reduce logistics cost and improve the economic benefit, and realize the warehousing green benefits and environmental benefits. (2) Specific to the internal layout of storage area, should be made according to the warehouse operation sequence, set up corresponding inventory acceptance, inventory, slow-moving area, such as functional partition, each partition are connected through the convenient channel, so

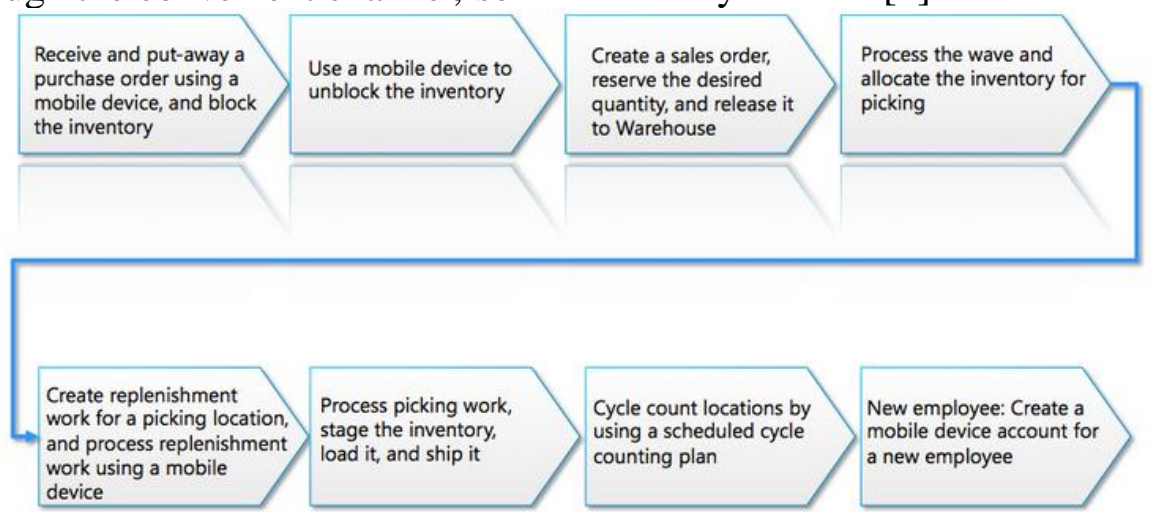

that the warehouse goods in and out in time to improve the whole efficiency of circulation of items in warehouse. (3) Warehouse construction should advocate green, environmental protection, the concept of sustainable, recyclable, comply with the principle of saving energy, water, land, construction materials, structural design, from warehouse roof power generation, and uses the implementation of the energy storage equipment with the storage of greening.

Warehousing companies will raise the level of technology and equipment. In the future, with the continuous development of the growing trade and modern logistics industry, in the center of storages processing quantity will increase a lot. This means that the speeding up of the loading frequency and receiving, placement, picking and basic shipping operations. Warehousing enterprises will focus on cultivating core competitiveness. In the fierce competition in today's logistics market, warehousing enterprises should take advantage of its unique advantages, and set up the core competitiveness of the enterprise, maintain the sustainable competitive advantage of the enterprise, to maintain and expand the existing market share. Warehousing enterprises will continue to pay attention to the management of the logistics information. The biggest difference between traditional and modern warehousing is the informationization management. Warehouse managers will put the goods, goods, sorting and the shipping operations as the most critical part of their job, they work in performing these, however, is difficult to obtain accurate information in a timely manner [6]. 
Figure 2. The General Procedures of the Modern Logistics Warehousing System

The Warehouse Management Concepts. Warehouse safety management is an important content of warehouse management, it is not only related to the storage of the materials, mechanical equipment safety, also affects people's health and safety, but also related to the production can proceed smoothly. Therefore, we must strengthen the safety management of the warehouse.

At present, the warehouse management cost is higher, and the low efficiency, serious impact on the development of the warehousing industry in China. Through the analysis found that the cause of these problems mainly include the following: spare parts warehouse space, warehouse storage space has not been fully utilized, lead to waste of situation; Process is not smooth, long in the warehouse operation process, the process is repeated, no specification, lead to low efficiency; Locale complex warehouse, the warehouse to carry on the design structure is unreasonable, when set up complex between various regions; Low degree of mechanization, the hardware is not much, transport of goods when involve the human resources. Therefore, the corresponding solutions are shown below.

- Warehouse location research. Warehouse location as a logistics enterprise important strategic decision, to improve the quality of logistics services to policymakers considering the location conditions, customer demand, the management efficiency of various factors that the specific implementation with the high complexity. To effectively simplify the warehouse site selection process, improve logistics enterprise decision-making, domestic and the foreign scholars from various angles, based on different methods and technology, many method is proposed.

- Warehouse layout research. Warehouse layout research in some of the constraint conditions, operating costs, transport distance, space utilization measures such as optimization method, it is generally regarded as the more variable, complex and the nonlinear constraint optimization problems, and prove is NP-hard problem. Kusiak think space within facility layout problem was widely seen as the facility layout problem, therefore, looking from the research venation warehouse layout problem research is considered to be a facility layout analysis method in the extension of warehouse management problems [7-8].

- The library distribution study. The library distribution as a warehouse to store the life cycle of an operation strategy, refers to the warehouse will receive the goods and other products will be shipped to the same place together delivery rather than long-term storage. Any intermediate point in the process of logistics only can realize the function of the consignee or the consignor capture and eliminate the goods storage and order.

In the process of material purchase, it is necessary to avoid the phenomenon of blind procurement, to ensure that purchased supplies quality according to company on the basis of need for procurement. If not the normal process of purchase, as the stipulated in the company is likely to cause the quality problem of the goods, after buying takes care of the problem, do not use the problems for a long time, will bring a lot of damage to the company, in the same way, if we don't timely procurement, unable to meet the needs of production in time, will also bring losses to the company. So it needs management and material management accounting coordinate in advance by the administrative department in the timely manner to convey shopping list and shopping requirements for general material management accounting, by the material management accounting and the related departments in strict accordance with the provisions of timely purchasing. 
The Implementation of the Warehouse Management System. Storage management in logistics management occupies the core position, it is a sign of imbalance between logistics each link, it is also address this imbalance. Warehousing link all the contradictions, focus on the process integration of upstream and downstream of the warehouse management is to realize the integration of the logistics process. In the figure one, we demonstrate the systematic architecture of the platform.

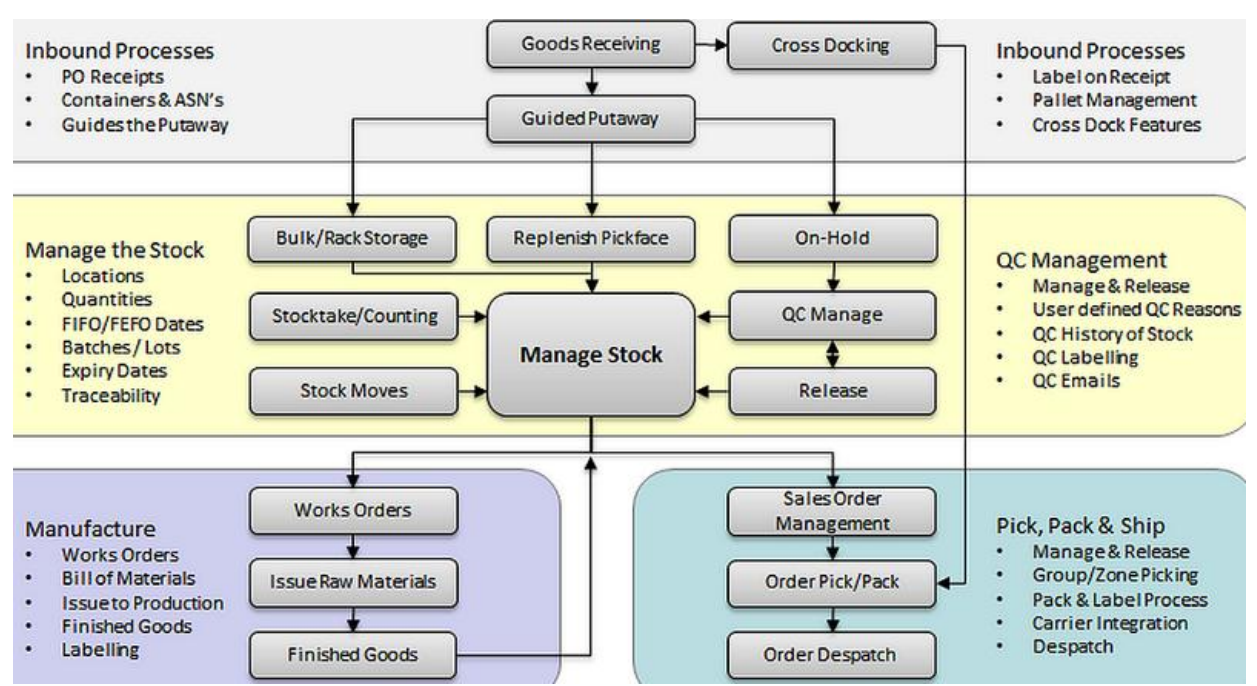

Figure 3. The Systematic Design of the Optimized Warehouse Management Platform

In the intelligent production logistics system, the intelligent distribution is on the cable production logistics management platform and offline production implementation of the important link that is the core of the production system performance. And intelligent distribution is the premise of to realize intelligent control of the bottleneck process to promote the primary intelligent distribution scheduling optimization that could be reflected from the listed aspects. (1) Inventory optimal control, hold a certain stock can make the enterprise to maintain production and ensure stability of selling products, balance the enterprise logistics and the cash flow. But at the same time, inventory takes up a lot of corporate capital, increase the enterprise's product cost and management cost. So today, top managers pay more and more attention to in business activities of enterprises in the supply chain, and inventory management is an important aspect of the whole supply chain, some management experts and even the logistics management is defined as static and movement of inventory management. (2) Warehouse operations, warehousing operation is the most basic part of the operation, not only to determine the control target and the management pattern to carry out the operation process, but also with a number of special storage equipment automatic control system of the cohesion, so also is the most technically complex part. Integration management strategy refers to the storage facilities and the social various suppliers, retailers, manufacturers, wholesalers, and even customer storage facilities for integration, optimize enterprise warehouse management strategy under supply chain management, warehousing management, to achieve to achieve the goal of optimization in the dynamic, on the premise of to meet customer requirements, to reduce inventory as far as possible to improve the overall efficiency.

\section{Conclusion}

In this paper, we conduct research on the logistics warehouse management system. Storage is the foundation of the companies material support departments. Warehousing department undertakes the supply enterprise production, construction of 
necessary goods, as are indispensable for the enterprise logistics department, thousands of the tons, hundreds of the millions of thousand worth of goods need through core professional logistics network timely, efficient, continuously supply to production and construction. Under the condition of the modern management, it is no longer in the general logistics department, but a strong technical and economic characteristics, connects production consumption of professional system, to the enterprise's production and construction plays an important guarantee and promote the role. Under this background, our research proposes the novel perspective of the logistics warehouse management system to achieve the better systematic performance for enterprises.

\section{References}

[1] Ekren, Banu Y., et al. "Simulation-based performance improvement of a defense logistics warehouse." International Material Handling Research Colloquium (IMHRC). 2012.

[2] Ye, Jing, Xifu Wang, and Zhaoyun Li. "Reverse Logistics Network Optimization Design under Fuzzy-stochastic Environment." LISS 2014. Springer Berlin Heidelberg, 2015. 1345-1352.

[3] Wei, Xiao Xiao. "Application Research of Internet of Things Technology in China Post
Modern Logistics Warehouse Management Based on RFID." Advanced Materials Research. Vol. 403. 2012.

[4] Roh, Sae-yeon, Hyun-mi Jang, and Chul-hwan Han. "Warehouse location decision factors in humanitarian relief logistics." The Asian Journal of Shipping and Logistics 29.1 (2013): 103-120.

[5] Zhou, Yan-cong, et al. "Routing optimization of intelligent vehicle in automated warehouse." Discrete Dynamics in Nature and Society 2014 (2014).

[6] [6] Li-Guo, Zhang. "Measurement and Analysis of Logistics Energy Efficiency in China from Perspective of Total Factor Productivity." Open Mechanical Engineering Journal 8 (2014): 624-629.

[7] Zhong, Xiao-Hong, et al. "Research on the Construction of the IOT System in the Field of Military Logistics." ICLEM 2012@ sLogistics for Sustained Economic Development-Technology and Management for Efficiency. ASCE, 2012.

[8] Jomaa, Dhia, Thiago Monteiro, and Beatrix Besombes. "Development of an inventory classification module: Implementation in a warehouse management system." Industrial Engineering and Systems Management (IESM), Proceedings of 2013 International Conference on. IEEE, 2013. 